\title{
Wnt/Fgf crosstalk is required for the specification of tracheal basal progenitor
}

\section{cells}

Zhili Hou ${ }^{1,2, \#}$, Qi Wu ${ }^{2, \#}$, Xin $\mathrm{Sun}^{2}$, Huaiyong $\mathrm{Chen}^{2}, \mathrm{Yu} \mathrm{Li}^{1,2}$, Yongchun Zhang ${ }^{1}$, Munemasa

Mori $^{1}$, Ying Yang ${ }^{1}$, Ming Jiang ${ }^{1, *}$, Jianwen Que ${ }^{1, *}$

1. Center for Human Development, Department of Medicine, Columbia University Medical Center, NY 10032, USA.

2. Tianjin Haihe Hospital, Tianjin 300350, P.R. China.

${ }^{*}$ Equal contribution

*Authors for correspondence: Ming Jiang (mj2735@cumc.columbia.edu); Jianwen Que (jq2240@cumc.columbia.edu)

\begin{abstract}
Basal progenitor cells are critical for the establishment and maintenance of the tracheal epithelium. However, it remains unclear how these progenitor cells are specified during foregut development. Here, we found that ablation of the Wnt chaperon protein Gpr177 (also known as Wntless) in the epithelium causes significant reduction in the numbers of basal progenitor cells accompanied by cartilage loss in Shh-Cre;Gpr $177^{\text {loxp/loxp }}$ mutants. Consistent with the association between cartilage and basal cell development, $\mathrm{Nkx} 2.1^{+} \mathrm{p} 63^{+}$basal cells are co-present with cartilage nodules in Shh-Cre;Ctnnb $1^{\text {DM/loxp }}$ mutants which keep partial cell-cell adhesion but not the transcription regulation function of B-catenin. More importantly, deletion of Ctnnb1 in the mesenchyme leads to the loss of basal cells and cartilage concomitant with the reduced transcript levels of Fgf10 in Dermo1-Cre;Ctnnb1 ${ }^{\text {loxp/loxp }}$ mutants. Furthermore, deletion of Fgf receptor 2 $(F g f r 2)$ in the epithelium also leads to significantly reduced numbers of basal cells, supporting the importance of the Wnt/Fgf crosstalk in early tracheal development.
\end{abstract}




\section{Introduction}

Basal cells are multipotent progenitor cells responsible for the generation of the airway epithelium during development and injury-repair (Hong et al., 2004; Que et al., 2009; Rock et al., 2009; Yang et al., 2018). Previous studies indicate that the epithelial-mesenchymal interactions are critical for basal cell development although the underlying molecular mechanism remains largely unknown (Hines et al., 2013; Volckaert et al., 2013). It has been shown that the numbers of basal cells are positively correlated with the differentiation of mesenchymal cells into cartilage at the early stage of tracheal development (Hines et al., 2013). Prior to the separation of the trachea from the anterior foregut, the growth factor Fgf10 is enriched in the ventral mesenchyme where cartilage progenitor cells arise (Que et al., 2007). Interestingly, ubiquitous Fgf10 overexpression promotes basal cell lineage commitment while suppressing ciliated cell differentiation (Volckaert et al., 2013). In addition, ubiquitous overexpression of the Wnt inhibitor Dkk1 at E10.5 but not E12.5 also leads to the increased numbers of basal cells (Volckaert et al., 2013). Wnt signaling is critical for initial specification of respiratory cells from the early foregut. Loss of Wnt2/2b which are enriched in the ventral foregut mesenchyme results in failed specification of respiratory progenitor cells $\left(\mathrm{Nkx} 2.1^{+}\right)$(Goss et al., 2009). Consistently, deletion of the canonical Wnt signaling mediator $\beta$-catenin also leads to lung and tracheal agenesis, and the anterior foregut becomes an esophageal-like tube lined with stratified squamous epithelium underlined by extensive basal progenitor cells (Goss et al., 2009; HarrisJohnson et al., 2009).

We and others previously showed that the respiratory cell fate is specified properly despite severe vasculature abnormalities following deletion of the Wnt chaperon protein Gpr177 (also known as Wntless) in Shh-Cre;Gpr $177^{\text {loxp/loxp }}$ mutants. Interestingly, in this study we found 
a significant loss of basal progenitor and cartilage cells in these mutants. Deletion of Ctnnbl encoding $\beta$-catenin in the mesenchyme also leads to the loss of basal progenitor cells and cartilage concomitant with the reduced levels of Fgfl0 in the trachea of DermolCre; $C$ tnnb1 $1^{\text {loxp/loxp }}$ mutants. Moreover, the numbers of basal progenitor cells are also significantly reduced when the Fgf10 receptor Fgfr2 is deleted in the epithelium. Together these findings support that in the developing trachea epithelial Wnts activate $\beta$-catenin in the mesenchyme to modulate Fgf10 levels which in turn regulate basal cell specification through epithelial Fgfr2.

\section{Results and Discussion}

Blocking Wnt secretion from the epithelium leads to a reduced number of basal progenitor cells and cartilage defects in the trachea of Shh-Cre;Gpr17 $17^{\text {loxp/loxp }}$ mutants.

We previously showed that deletion of Gpr177 in the epithelium results in the abnormal differentiation and proliferation of vascular smooth muscle cells in the developing lung, and the mutants succumb at birth due to severe pulmonary hemorrhage (Jiang et al., 2013). A recent study demonstrated that deletion of Gpr177 also leads to tracheal cartilage defects in these mutants (Snowball et al., 2015). We asked whether basal cell specification is affected upon Gpr177 deletion given the correlation of cartilage and basal cell numbers (Hines et al., 2013). Consistent with previous findings (Snowball et al., 2015), Gpr177 deletion results in the loss of cartilage progenitor cells $\left(\mathrm{Sox} 9^{+}\right)$while smooth muscle cells $\left(\mathrm{SMA}^{+}\right)$are expanded in the trachea of Shh-Cre;Gpr $177^{\text {loxp/loxp }}$ mutants (Fig. 1A-B). Intriguingly, basal cells (p63 ${ }^{+}$) are rarely detected in the trachea of Shh-Cre;Gpr177 $7^{\text {loxp/loxp }}$ mutants at different developing stages examined (Fig. 1A-B, $n=3$ for each stage). These results suggest that Wnts from the epithelium act in both autocrine and paracrine manners to regulate tracheal development. Notably, Gpr177 deletion did 
not to affect the specification of respiratory cells from the early foregut and all the epithelial cells express Nkx2.1 (Fig. 1A-B). Increased differentiation of ciliated ( $\alpha$-acetylated tubulin ${ }^{+}$) but not club cells $\left(\mathrm{Cc}^{+} 0^{+}\right)$was also observed in the tracheal epithelium at late stage (Fig. 1B). In addition, although loss of Gpr177 leads to the reduced proliferation of both epithelial and mesenchymal cells, the difference between mutants and wildtype controls is not significant (Fig. $1 \mathrm{C}, \mathrm{p}>0.05$, $\mathrm{n}=3$ for each).

\section{Presence of tracheal basal cells $\left(\mathrm{Nkx} 2.1^{+} \mathrm{p63}{ }^{+}\right)$and cartilage nodules in the unseparated foregut of Shh-Cre; Ctnnb1 $1^{D M / l o x p}$ mutants}

$\beta$-catenin has two major roles, mediating Wnt-activated transcription regulation and cell-cell adhesion functions (Heuberger and Birchmeier, 2010). Thus far genetic studies assessing the role of $\beta$-catenin in the developing lung have relied on the $C$ tnnbl $1^{\text {loxp }}$ allele which ablates both transcription regulation and cell-cell adhesion functions upon Cre-mediated recombination (Brault et al., 2001; De Langhe et al., 2008; Goss et al., 2009; Stenman et al., 2008). Although many of the phenotypic changes seem to recapitulate what have been observed in mutants lacking Wnt ligands (Goss et al., 2009; Stenman et al., 2008), it is unclear whether the cell-cell adhesive function of $\beta$-catenin contributes to lung and tracheal development.

Another mouse line containing a mutated Ctnnbl allele (Ctnnb1 double mutant; hereafter referred as $C t n n b 1^{D M}$ ) was recently established (Valenta et al., 2011). This mutant form of $\beta$ catenin includes a single amino acid change (aspartic acid mutated to Alanine, D164A) in the first Armadillo repeat of $\beta$-catenin, which prevents TCF-dependent transcription regulation while maintaining the ability to mediate cellular adhesion (Valenta et al., 2011). Notably, Ctnnb1 ${ }^{D M / D M}$ mutants die at E10.5 (Gay et al., 2015). We combined this allele with the $C \operatorname{tnnb} 1^{\text {loxp }}$ allele to 
address whether ß-catenin acts in the epithelium to regulate basal cell development. As expected, $\beta$-catenin protein is retained in the epithelial junction of Shh-Cre;Ctnnb1 ${ }^{\text {DM/loxp }}$ but not ShhCre;Ctnnb1 $1^{\text {loxp/loxp }}$ mutants (Fig. S1). Similar to Shh-Cre;Ctnnb1 ${ }^{\text {loxp/loxp }}$ mutants, the anterior foregut remains a single-lumen tube in Shh-Cre;Ctnnb1 $1^{D M / l o x p}$ embryos (Fig. 2A). Consistent with previous findings (Goss et al., 2009; Harris-Johnson et al., 2009), the unseparated foregut is specified as an esophageal-like muscular tube lined by squamous basal cells $\left(\mathrm{Nkx} 2.1^{-} \mathrm{p} 63^{+}\right)$in Shh-Cre;Ctnnb1 $1^{\text {loxp/loxp }}$ mutants (Fig. 2B). By contrast, the ventral side of the unseparated foregut in Shh-Cre;Ctnnb1 $1^{\text {DM/loxp }}$ mutants demonstrates respiratory cell differentiation $\left(\mathrm{Nkx} 2.1^{+}\right)$ underlined by cartilage nodules $\left(\operatorname{Sox} 9^{+}\right)$(Fig. 2C). These ventral epithelial cells express the columnar cell marker Krt8, but not the squamous cell marker Krt13 (Fig. S2B). More importantly, tracheal basal cells $\left(\mathrm{Nkx} 2.1^{+} \mathrm{p} 63^{+}\right)$are present in the proximity of the cartilage nodules, confirming the association of cartilage and basal cell development (Hines et al., 2013). Of note is that some residual ciliated and club cells are also present in the ventral foregut of ShhCre;Ctnnb1 $1^{\text {DM/loxp }}$ mutants (Fig. S2C). Taken together these results suggest that the cellular adhesion function of $\beta$-catenin plays roles in tracheal development. That being said, we can't rule out the possibility that some residual $ß$-catenin mediated transcription regulation activities remain present in Shh-Cre;Ctnnb1 $1^{D M / l o x p}$ mutants, even though TCF-transactivation dependent Wnt signaling is ablated in various studies using the $C t n n b 1^{D M}$ mouse line (Azim et al., 2014; Gay et al., 2015; Valenta et al., 2016; Valenta et al., 2011).

Epithelial Wnts regulate basal cell and cartilage development through mesenchymal Bcatenin 
Loss of epithelial Wnts inhibits the development of tracheal cartilage and basal cells in Shh-Cre; Gpr $177^{\text {loxp/loxp }}$ mutants. We asked whether epithelial Wnts directly regulate basal cell and cartilage development through $\beta$-catenin in the mesenchyme. We deleted $\beta$-catenin with Dermo1-Cre which is active in the mesenchymal progenitor cells as early as E10.5 (Hines et al., 2013; Sala et al., 2011). As previously described, the trachea is separated from the early foregut but is shortened, accompanied by simplified lung branching morphogenesis in Dermol-Cre; Ctnnb1 $1^{\text {loxp/loxp }}$ mutants (De Langhe et al., 2008). Interestingly, cartilage progenitor cells (Sox $9^{+}$) are absent in the trachea of mutants at E11.5 (Fig. 3A). Sox9 immunostaining further confirmed the loss of cartilage at E14.5 (Fig. 3A). By contrast, smooth muscle cells (SMA ${ }^{\dagger}$ ) extend to the ventral side of the trachea (Fig. 3A). Loss of cartilage is accompanied by significant reduction in the number of basal progenitor cells which were barely detected in the trachea at E11.5 $(n=3)$ and E14.5 (n=5) (Fig. 3B). Notably, p63 ${ }^{+}$cells are also barely detected in the ventral foregut epithelium prior to the separation of the trachea from the foregut (Fig. 3B). Together these data support that $\beta$-catenin in the mesenchyme is a critical mediator for epithelial Wnts to regulate cartilage and basal cell specification in the developing trachea.

\section{Mesenchymal B-catenin regulates basal cell specification through crosstalk with}

\section{Fgf10/Fgfr2 signaling}

Previous studies have shown that Fgf10 overexpression leads to an increased number of basal cells in the airways (Volckaert et al., 2013). We therefore asked whether the transcript levels of

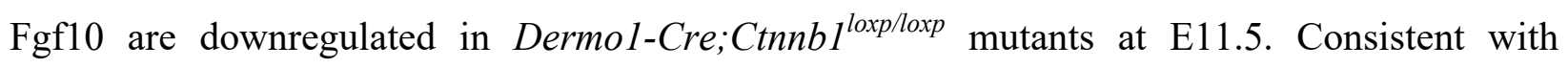
mitigated Wnt activities, the transcript levels of the Wnt/ $\beta$-catenin downstream targets Axin 2 and Lef1 are significantly decreased (Fig. 4A). Interestingly, we also observed dramatical reduction 
in the transcript levels of Fgf10 upon Ctnnb1 deletion in the mesenchyme (Fig. 4A). Previously we and others have shown that Fgf10 is expressed in the ventral mesenchyme of the foregut prior to tracheal-esophageal separation and then restricted to the inter-cartilage compartment after tracheal cartilage condensation occurs (Que et al., 2007; Sala et al., 2011). By contrast, the Fgf10 receptor Fgfr2 is uniformly expressed in the epithelium (Sala et al., 2011). We hypothesized that decreased Fgf signaling contributes to the loss of basal cells in Dermol-Cre;Ctnnb1 ${ }^{\text {loxp/loxp }}$ mutants. We therefore deleted Fgfr2 in the early foregut epithelium using Shh-Cre. Consistent with previous finding, loss of Fgfr2 leads to lung agenesis and truncated trachea (Sala et al., 2011). Conditional loss of Fgfr2 also leads to less condensed cartilage although the alternative pattern of smooth muscle and cartilage seems not perturbed (Fig. 4B). Importantly, similar to what has been observed in Dermol-Cre;Ctnnb1 $1^{\text {loxp/loxp }}$ mutants, the numbers of basal cells are significantly reduced in the trachea of Shh-Cre;Fgfr $2^{\text {loxp/loxp }}$ mutants (Fig. 4C). These findings support a model whereby Fgf10 from the mesenchyme under the control of $\beta$-catenin is critical for the specification of basal cells in the developing trachea. A crosstalk between Hippo signaling and Fgf10 has been shown to regulate basal cell-fueled epithelial regeneration in the adult trachea (Volckaert et al., 2017). Here, our findings support that the $\beta$-catenin/Fgf10/Fgfr2 axis plays an important role in basal cell specification during early tracheal development.

In summary, our study revealed that Wnt proteins secreted from the respiratory epithelium is critical for both tracheal cartilage and basal cell development. We found residual ßcatenin, presumably mediating cell-cell adhesion function is critical for the specification of tracheal epithelium and cartilage development in Shh-Cre;Ctnnb1 ${ }^{\text {DM/loxp }}$ mutants. On the other hand, $\beta$-catenin in the mesenchyme plays significant roles in the specification of basal progenitor cells and cartilage. Our further genetic studies suggest that mesenchymal ß-catenin regulates 
Fgf10 which relays to its receptor Fgfr2 in the epithelium to regulate basal cell specification (Fig. 4D).

\section{Acknowledgement}

We are grateful that Dr. Konrad Basler (University of Zurich) shared with us the Ctnnb1 $1^{D M}$ mouse line. This work is partly supported by R01HL132996 and the Price Family Foundation.

\section{Competing interests}

The authors declare no competing financial interests.

\section{Author contributions}

M.J. and J.Q. designed experiments, analyzed data, and wrote the manuscript. Z.H. and M.J. performed the experiments. M.M. provided Shh-Cre;Fgfr $2^{\text {loxp/loxp }}$ embryos. Q.W., X.S., H.C., Y.Z. Y.L., and Y.Y. assisted with mouse genetics.

\section{Figure Legends}

Fig. 1. Loss of epithelial Wnt secretion leads to abnormal development of tracheal cartilage and basal cell. (A) Loss of epithelial Gpr177 causes dramatic reduction in the numbers of cartilage progenitor cells $\left(\mathrm{Sox} 9^{+}\right)$and basal cells $\left({\left.\mathrm{p} 63^{+}\right)}\right.$in the trachea of Shh-Cre; Gpr $177^{\text {loxp/loxp }}$ mutant at E12.5. (B) Loss of epithelial Gpr177 leads to the loss of cartilage (Alcian Blue ${ }^{+}$Sox $9^{+}$) and reduction in the number of basal cells at E17.5. Note the increased number of ciliated cells in the mutant trachea. (C) The proliferation of both epithelial and mesenchymal cells is slightly but not significantly decreased in the mutant trachea $(p>0.05 n=3$ for each). Data are represented as mean \pm SEM. Abbreviation: Es: esophagus; Tr: trachea. Scale Bar: $50 \mu \mathrm{m}$. 
Fig. 2. Residual tracheal basal cells and cartilage nodules in Shh-Cre; Gpr177 ${ }^{\text {DM/loxp }}$ mutants. (A) Failed separation of the trachea and esophagus in Shh-Cre; Gpr $177^{\text {loxp/loxp }}$ $\left(C t n n b 1^{C K O}\right)$ and Shh-Cre; Gpr $177^{D M / l o x p}\left(C t n n b 1^{D K O}\right)$ mutants. Note the stratified squamous epithelium lining the muscular tube in $C \operatorname{tnnb1} 1^{C K O}$ mutants and residual cartilage nodules (Alcian blue $\left.{ }^{+}\right)$in $C t n n b 1^{D K O}$ mutants. (B) Tracheal basal cells $\left(\mathrm{Nkx} 2.1^{+} \mathrm{p} 63+\right)$ are present in the ventral side of the unseparated foregut in $C_{t n n b 1}{ }^{D K O}$ but not $C t n n b 1^{C K O}$ mutants. (C) Residual respiratory epithelium $\left(\mathrm{Nkx} 2.1^{+}\right)$is underlined by cartilage nodules (Sox $\left.9^{+}\right)$in $C t n n b 1^{D K O}$ mutants. Abbreviation: Es, esophagus; Tr, Trachea; St, single lumen tube. Scale bar: $50 \mu \mathrm{m}$.

Fig. 3. Deletion of Ctnnb1 in the mesenchyme causes the loss of tracheal cartilage and basal cells in Dermo1-Cre; Ctnnb1 $^{\text {loxp/loxp }}$ mutants. (A) Tracheal cartilage is absent in Dermol-Cre; Ctnnb1 $1^{\text {loxp/loxp }}$ mutants. Note some neuronal-like cells $\left(\right.$ Sox $\left.9^{+}\right)$in the mutant trachea. (B) Basal cells are barely detected in both ventral and dorsal sides of the mutant trachea at different developmental stages. Abbreviation: Es, esophagus; Tr, trachea; Ca, cartilage; $D$, dorsal; $V$, ventral. Scale bar: $50 \mu \mathrm{m}$.

Fig. 4. Mesenchymal $\beta$-catenin regulates the specification of basal cell through Fgf10/Fgfr2 signaling. (A) The reduced transcript levels of the Wnt/ $\beta$-catenin downstream targets Axin2 and Lef1 and Fgf10 in the trachea of Dermo1-Cre; Ctnnb1 ${ }^{\text {loxp/loxp }}$ mutants $\left({ }^{*} p<0.05 ; * * p<0.01 ; n=3\right.$ independent experiments). (B) Deletion of Fgfr2 leads to less-condensed cartilage in the trachea of Shh-Cre; Fgfr $2^{\text {loxp/loxp }}$ mutants. (C) Loss of Fgfr2 causes significant reduction in the number of basal cells (arrowheads). (D) Diagram depicts that the epithelial-mesenchymal interaction mediated by $\mathrm{Wnt} / \beta$-catenin signaling regulates tracheal basal cell and cartilage development. Epithelial Wnt proteins directly activate mesenchymal $\beta$-catenin to promote the expression of 
Fgf10 which in turn activates epithelial Fgfr2 to modulate basal cell specification. Abbreviation:

Tr: trachea; Epi: epithelium; Mes: mesenchyme. Scale bar: $50 \mu \mathrm{m}$.

Fig. S1. $\beta$-catenin protein is retained in the epithelial junction of $C \operatorname{Cnn} b 1^{D K O}$ but not Ctnnb1 $^{\text {CKO }}$ mutants. Abbreviation: Es: esophagus; Tr: trachea; St: single lumen tube; CKO: Shh-Cre;Ctnnb1 $1^{\text {loxp/loxp }} ;$ DKO: Shh-Cre;Ctnnb1 $1^{\text {DM/loxp }}$. Scale bar: $50 \mu \mathrm{m}$.

Fig. S2. Presence of residual respiratory epithelium in the unseparated foregut tube in Ctnnb1 ${ }^{\text {DKo }}$ but not $C \operatorname{Cnnb1} 1^{C K O}$ mutants. (A) Presence of cartilage nodules in $C \operatorname{tnn} b 1^{D K O}$ but not Ctnnb1 ${ }^{C K O}$ mutants. Note expanded smooth muscle cells in the foregut of both $C t n n b 1^{C K O}$ and $C t n n b 1^{D K O}$ mutants. (B) The residual respiratory epithelial cells in $C t n n b 1^{D K O}$ mutants express the columnar cell marker Krt8, but not the squamous cell protein Krt13 which is enriched throughout the esophagus-like tube in $C t n n b 1^{C K O}$ mutants. (C) Presence of club cells $\left(\mathrm{Cc} 10^{+}\right)$ and ciliated cells (a-tubulin ${ }^{+}$) in the ventral side of the unseparated foregut of $C \operatorname{tnn} b 1^{D K O}$ mutants at E18.5. Abbreviation: Es, esophagus; Tr, trachea; Br, bronchus; St, single lumen tube; $C K O$ : Shh-Cre;Ctnnb1 $1^{\text {loxp/loxp }} ;$ DKO: Shh-Cre;Ctnnb1 $1^{\text {DM/loxp }}$. Scale bar: $50 \mu \mathrm{m}$.

\section{Materials and Methods}

\section{Mice}

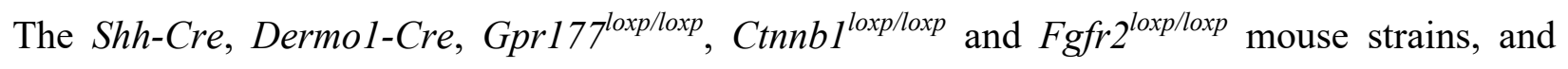
genotyping methods have been reported previously (Brault et al., 2001; Fu et al., 2009; Harfe et al., 2004; Yu et al., 2003). Ctnnb $1^{D M /+}$ mice were kindly provided by Dr. Konrad Basler of University of Zurich (Valenta et al., 2011). All mice were maintained in the University's animal 
facility according to institutional guidelines. All mouse experiments were conducted in accordance with procedures approved by the Institutional Animal Care and Use Committee.

\section{Tissue processing, histology and immunostaining}

For paraffin sections, tissues were fixed in $4 \%$ paraformaldehyde overnight and processed as previously described (Jiang et al., 2017). For cryo-sections, tissues were fixed in 4\% paraformaldehyde in PBS at $4^{\circ} \mathrm{C}$ overnight, placed in $30 \%$ sucrose in PBS, and embedded in OCT. The primary antibodies used for immunostaining analysis include: rabbit anti-Nkx2.1 (1:500, ab76013, Abcam); mouse anti-p63 (1:500, CM163, Biocare); rabbit anti-Sox9 (1:1000, AB5535, Millipore); mouse anti-smooth muscle actin (SMA) (1:2000, A2547, Sigma); chicken anti-KRT8 (1:1000, ab107115, Abcam); rabbit anti-Krt13 (1:1000, ab92551, Abcam); rabbit anti- $\beta$-catenin (1:200, 8480S, Cell Signaling Technology); rabbit anti-Cc10 (1:500, 06-263, Millipore); mouse anti- $\alpha$-acetylated tubulin (1:5000, T7451, Sigma); mouse anti-Ki67 (1:500, 550609, BD Biosciences). Fluorescent secondary antibodies were used for detection and visualization. Images were obtained using Nikon SMZ1500 Inverted microscope (Nikon). Confocal images were obtained with a Zeiss LSM T-PMT confocal laser-scanning microscope (Carl Zeiss).

\section{Alcian blue staining}

Whole lungs were dissected in PBS solution and fixed in 95\% EtOH. Alcian blue staining was performed as previously described (Jiang et al., 2017). Briefly, whole lungs and sections were treated with 3\% acetic acid solution for 3 minutes, then stained in Alcian blue (A3157, Sigma) for 5 minutes and counterstained with Nuclear Fast Red (N8002, Sigma).

\section{Reverse transcription and real-time PCR}


RNA extraction and reverse transcription was performed using the Super-Script III First-Strand SuperMix (Invitrogen) according to the manufacturer's instructions. cDNA was subjected to quantitative real-time PCR using the StepOnePlus Real-Time PCR Detection System (Applied Biosystems) and iTaq Universal SYBR Green Supermix (Bio-Rad). All real-time quantitative PCR experiments were performed in triplicate. The prime sequences were as follows: $\beta$-actin forward 5'-CGGCCAGGTCATCACTATTGGCAAC-3' and reverse 5'GCCACAGGATTCCATACCCAA-3'; Axin2 forward 5'-CAGCCCTTGTGGTTCAAGCT and reverse 5'-GGTAGATTCCTGATGGCCGTAGT-3'; Lef1 forward 5'GCAGCTATCAACCAGATCC-3' and 5'-GATGTAGGCAGCTGTCATTC-3'; Fgf10 forward 5'-CGGGACCAAGAATGAAGACT-3' and reverse 5'-AGTTGCTGTTGATGGCTTTG-3'.

\section{Statistical analysis}

Statistical analysis was done by Student's t-test. Data are presented as mean \pm s.e.m.; p values $<$ 0.05 were considered statistically significant.

\section{References}

Azim, K., Fischer, B., Hurtado-Chong, A., Draganova, K., Cantu, C., Zemke, M., Sommer, L., Butt, A., Raineteau, O., 2014. Persistent Wnt/beta-catenin signaling determines dorsalization of the postnatal subventricular zone and neural stem cell specification into oligodendrocytes and glutamatergic neurons. Stem Cells 32, 1301-1312.

Brault, V., Moore, R., Kutsch, S., Ishibashi, M., Rowitch, D.H., McMahon, A.P., Sommer, L., Boussadia, O., Kemler, R., 2001. Inactivation of the beta-catenin gene by Wnt1-Cre-mediated deletion results in dramatic brain malformation and failure of craniofacial development. Development 128, 1253-1264.

De Langhe, S.P., Carraro, G., Tefft, D., Li, C., Xu, X., Chai, Y., Minoo, P., Hajihosseini, M.K., Drouin, J., Kaartinen, V., Bellusci, S., 2008. Formation and differentiation of multiple mesenchymal lineages during lung development is regulated by beta-catenin signaling. PLoS One 3, e1516.

Fu, J., Jiang, M., Mirando, A.J., Yu, H.M., Hsu, W., 2009. Reciprocal regulation of Wnt and Gpr177/mouse Wntless is required for embryonic axis formation. Proc Natl Acad Sci U S A 106, 18598-18603.

Gay, M.H., Valenta, T., Herr, P., Paratore-Hari, L., Basler, K., Sommer, L., 2015. Distinct adhesionindependent functions of beta-catenin control stage-specific sensory neurogenesis and proliferation. BMC Biol 13, 24. 
Goss, A.M., Tian, Y., Tsukiyama, T., Cohen, E.D., Zhou, D., Lu, M.M., Yamaguchi, T.P., Morrisey, E.E., 2009. Wnt2/2b and beta-catenin signaling are necessary and sufficient to specify lung progenitors in the foregut. Dev Cell 17, 290-298.

Harfe, B.D., Scherz, P.J., Nissim, S., Tian, H., McMahon, A.P., Tabin, C.J., 2004. Evidence for an expansionbased temporal Shh gradient in specifying vertebrate digit identities. Cell 118, 517-528.

Harris-Johnson, K.S., Domyan, E.T., Vezina, C.M., Sun, X., 2009. beta-Catenin promotes respiratory progenitor identity in mouse foregut. Proc Natl Acad Sci U S A 106, 16287-16292.

Heuberger, J., Birchmeier, W., 2010. Interplay of cadherin-mediated cell adhesion and canonical Wnt signaling. Cold Spring Harb Perspect Biol 2, a002915.

Hines, E.A., Jones, M.K., Verheyden, J.M., Harvey, J.F., Sun, X., 2013. Establishment of smooth muscle and cartilage juxtaposition in the developing mouse upper airways. Proc Natl Acad Sci U S A 110, 1944419449.

Hong, K.U., Reynolds, S.D., Watkins, S., Fuchs, E., Stripp, B.R., 2004. Basal cells are a multipotent progenitor capable of renewing the bronchial epithelium. Am J Pathol 164, 577-588.

Jiang, M., Ku, W.Y., Fu, J., Offermanns, S., Hsu, W., Que, J., 2013. Gpr177 regulates pulmonary vasculature development. Development 140, 3589-3594.

Jiang, M., Li, H., Zhang, Y., Yang, Y., Lu, R., Liu, K., Lin, S., Lan, X., Wang, H., Wu, H., Zhu, J., Zhou, Z., Xu, J., Lee, D.K., Zhang, L., Lee, Y.C., Yuan, J., Abrams, J.A., Wang, T.C., Sepulveda, A.R., Wu, Q., Chen, H., Sun, X., She, J., Chen, X., Que, J., 2017. Transitional basal cells at the squamous-columnar junction generate Barrett's oesophagus. Nature 550, 529-533.

Que, J., Luo, X., Schwartz, R.J., Hogan, B.L., 2009. Multiple roles for Sox2 in the developing and adult mouse trachea. Development 136, 1899-1907.

Que, J., Okubo, T., Goldenring, J.R., Nam, K.T., Kurotani, R., Morrisey, E.E., Taranova, O., Pevny, L.H., Hogan, B.L., 2007. Multiple dose-dependent roles for Sox2 in the patterning and differentiation of anterior foregut endoderm. Development 134, 2521-2531.

Rock, J.R., Onaitis, M.W., Rawlins, E.L., Lu, Y., Clark, C.P., Xue, Y., Randell, S.H., Hogan, B.L., 2009. Basal cells as stem cells of the mouse trachea and human airway epithelium. Proc Natl Acad Sci U S A 106, 12771-12775.

Sala, F.G., Del Moral, P.M., Tiozzo, C., Alam, D.A., Warburton, D., Grikscheit, T., Veltmaat, J.M., Bellusci, S., 2011. FGF10 controls the patterning of the tracheal cartilage rings via Shh. Development 138, 273282.

Snowball, J., Ambalavanan, M., Whitsett, J., Sinner, D., 2015. Endodermal Wnt signaling is required for tracheal cartilage formation. Dev Biol 405, 56-70.

Stenman, J.M., Rajagopal, J., Carroll, T.J., Ishibashi, M., McMahon, J., McMahon, A.P., 2008. Canonical Wnt signaling regulates organ-specific assembly and differentiation of CNS vasculature. Science 322, 1247-1250.

Valenta, T., Degirmenci, B., Moor, A.E., Herr, P., Zimmerli, D., Moor, M.B., Hausmann, G., Cantu, C., Aguet, M., Basler, K., 2016. Wnt Ligands Secreted by Subepithelial Mesenchymal Cells Are Essential for the Survival of Intestinal Stem Cells and Gut Homeostasis. Cell Rep 15, 911-918.

Valenta, T., Gay, M., Steiner, S., Draganova, K., Zemke, M., Hoffmans, R., Cinelli, P., Aguet, M., Sommer, L., Basler, K., 2011. Probing transcription-specific outputs of beta-catenin in vivo. Genes Dev 25, 26312643.

Volckaert, T., Campbell, A., Dill, E., Li, C., Minoo, P., De Langhe, S., 2013. Localized Fgf10 expression is not required for lung branching morphogenesis but prevents differentiation of epithelial progenitors. Development 140, 3731-3742.

Volckaert, T., Yuan, T., Chao, C.M., Bell, H., Sitaula, A., Szimmtenings, L., El Agha, E., Chanda, D., Majka, S., Bellusci, S., Thannickal, V.J., Fassler, R., De Langhe, S.P., 2017. Fgf10-Hippo Epithelial-Mesenchymal Crosstalk Maintains and Recruits Lung Basal Stem Cells. Dev Cell 43, 48-59 e45. 
Yang, Y., Riccio, P., Schotsaert, M., Mori, M., Lu, J., Lee, D.K., Garcia-Sastre, A., Xu, J., Cardoso, W.V., 2018. Spatial-Temporal Lineage Restrictions of Embryonic p63(+) Progenitors Establish Distinct Stem Cell Pools in Adult Airways. Dev Cell 44, 752-761 e754.

Yu, K., Xu, J., Liu, Z., Sosic, D., Shao, J., Olson, E.N., Towler, D.A., Ornitz, D.M., 2003. Conditional inactivation of FGF receptor 2 reveals an essential role for FGF signaling in the regulation of osteoblast function and bone growth. Development 130, 3063-3074. 
Fig. 1

A
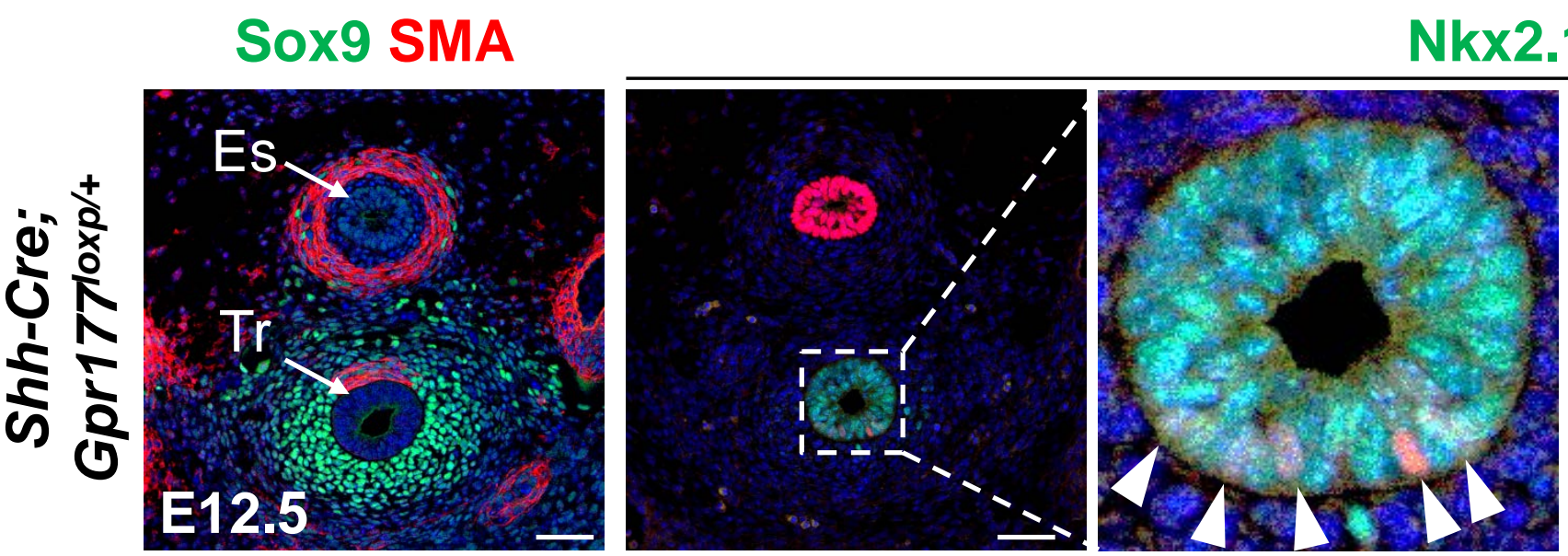

Nkx2.1 p63
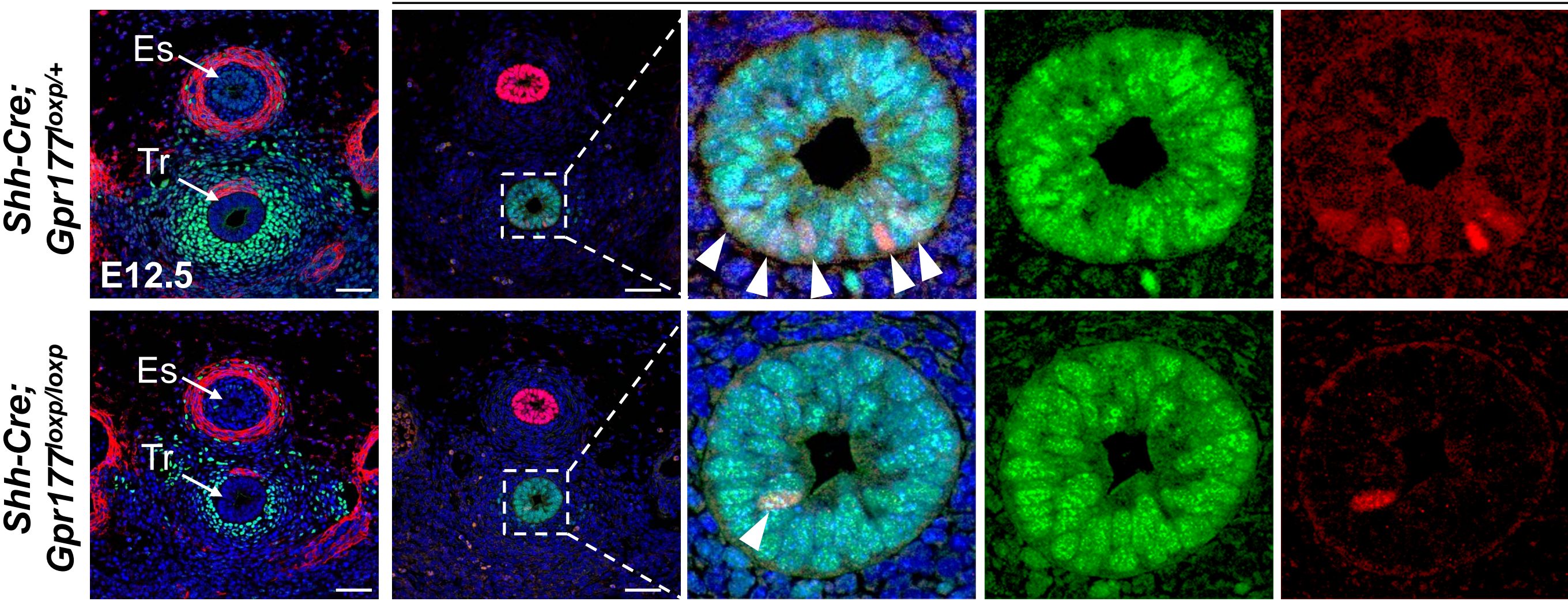

B

H\&E

Alcian blue

Sox9 SMA
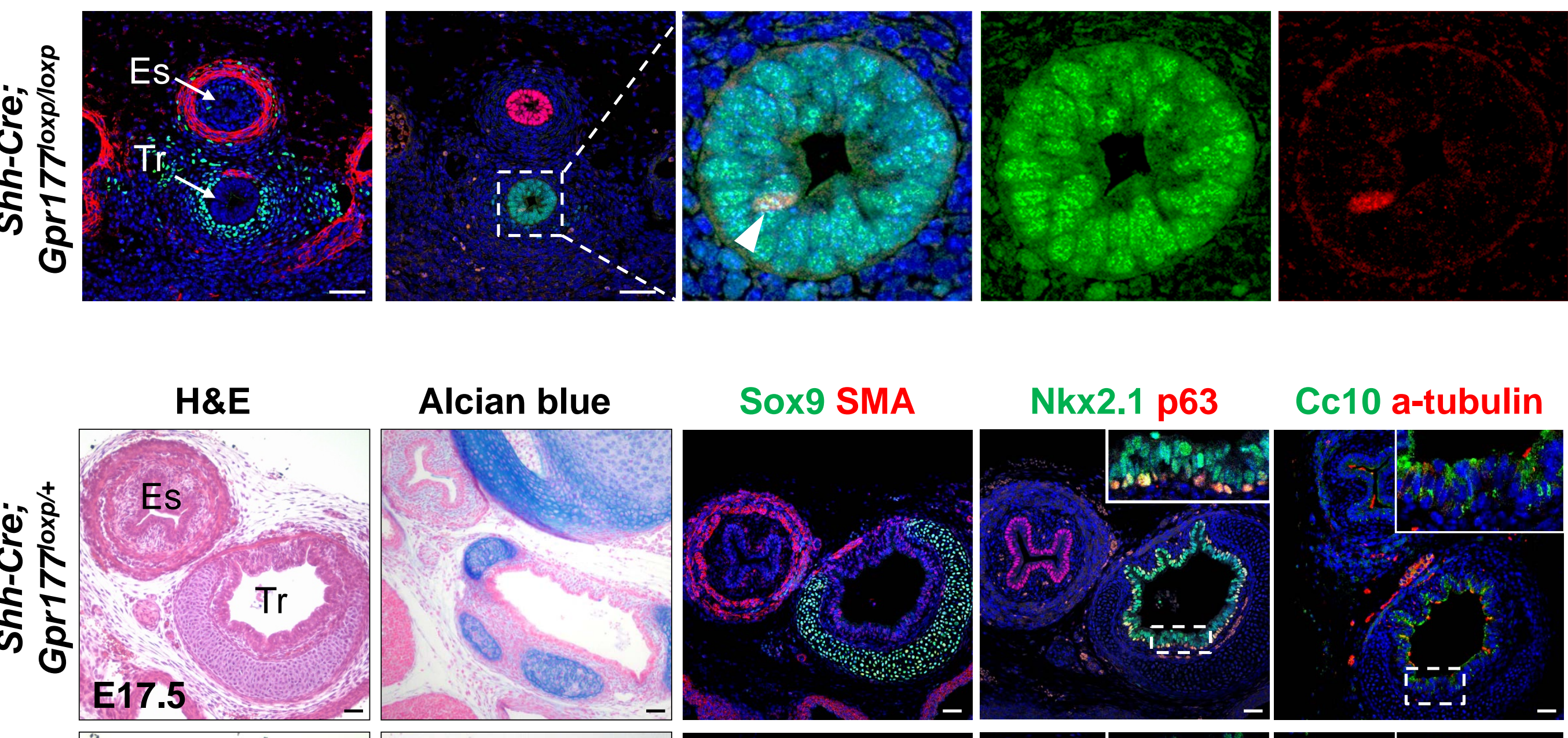

Nkx2.1 p63

Cc10 a-tubulin

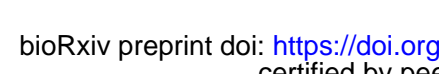

2
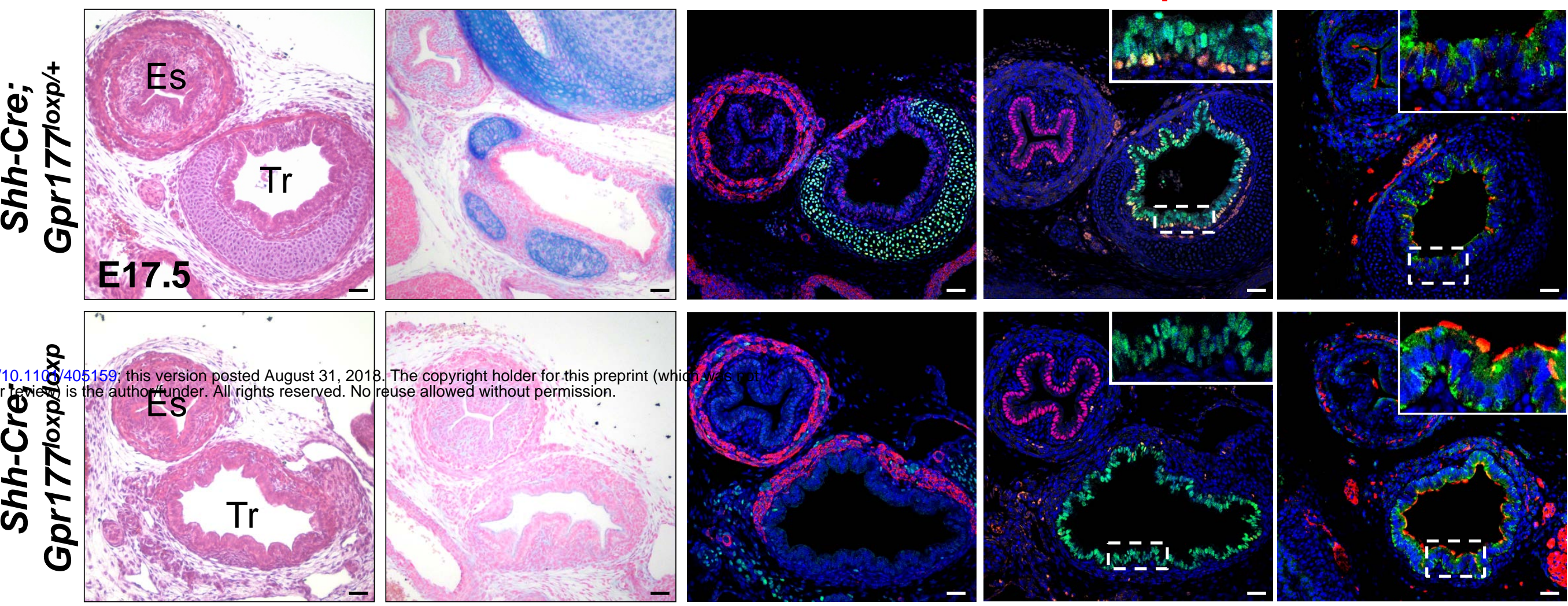

C
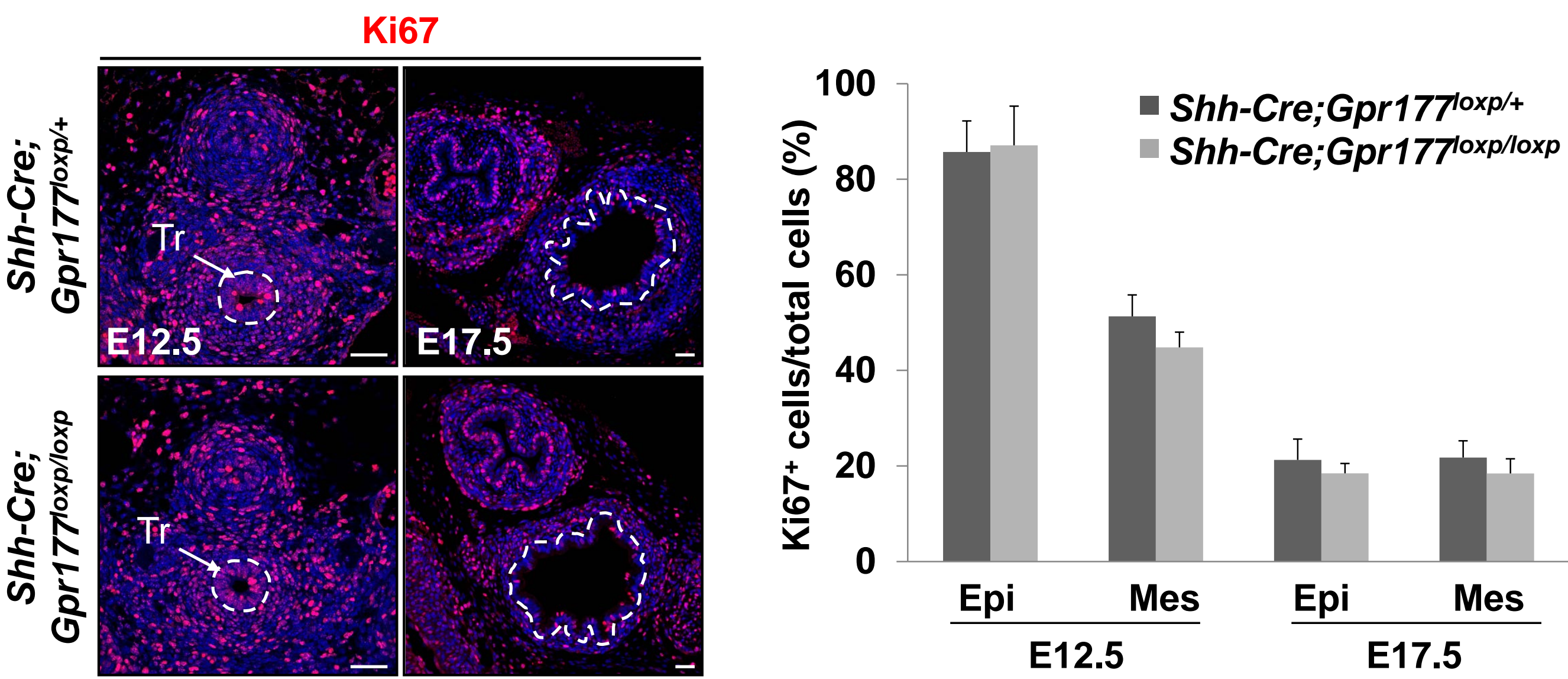
Fig. 2

A

H\&E
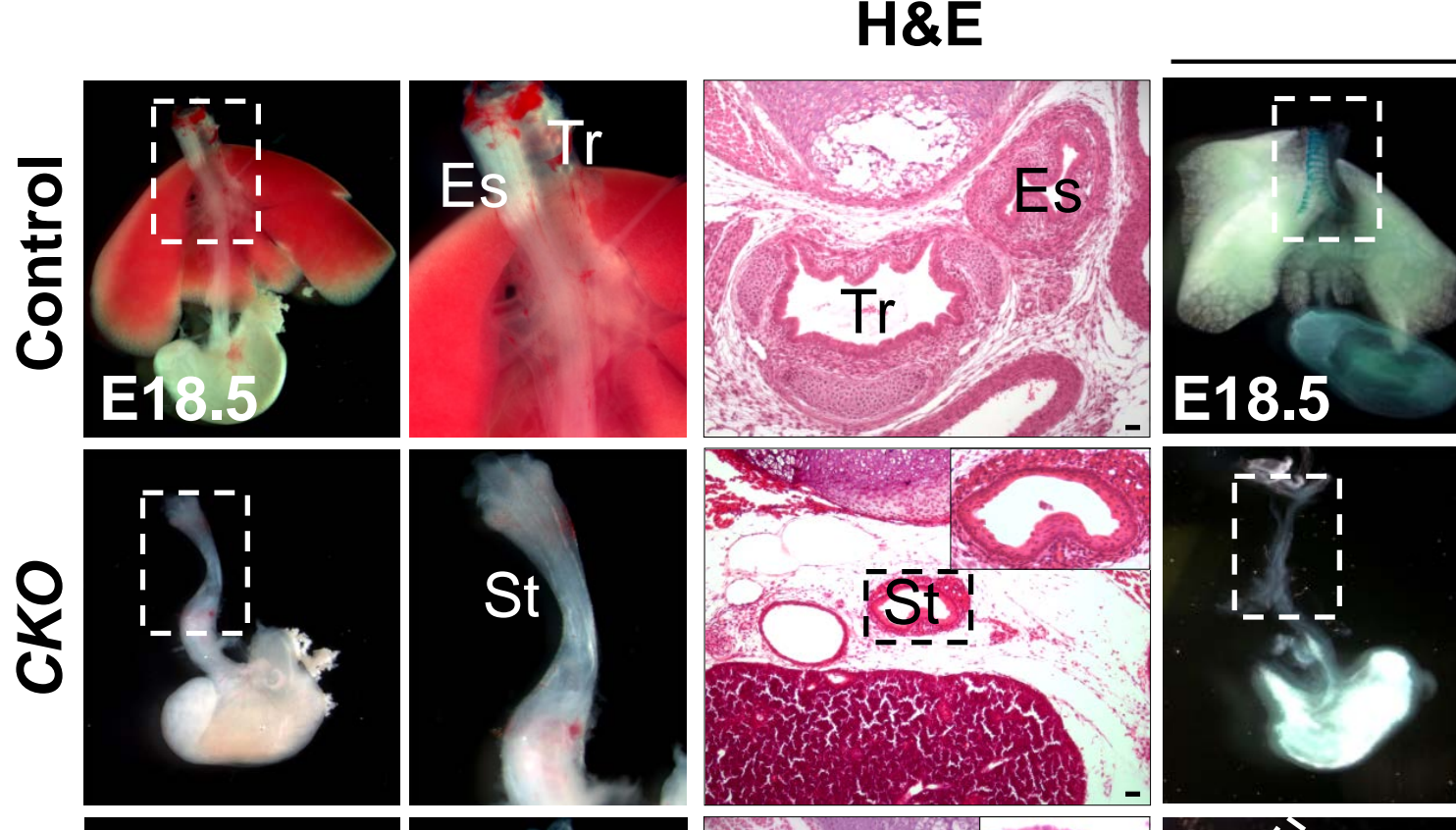

Alcian blue
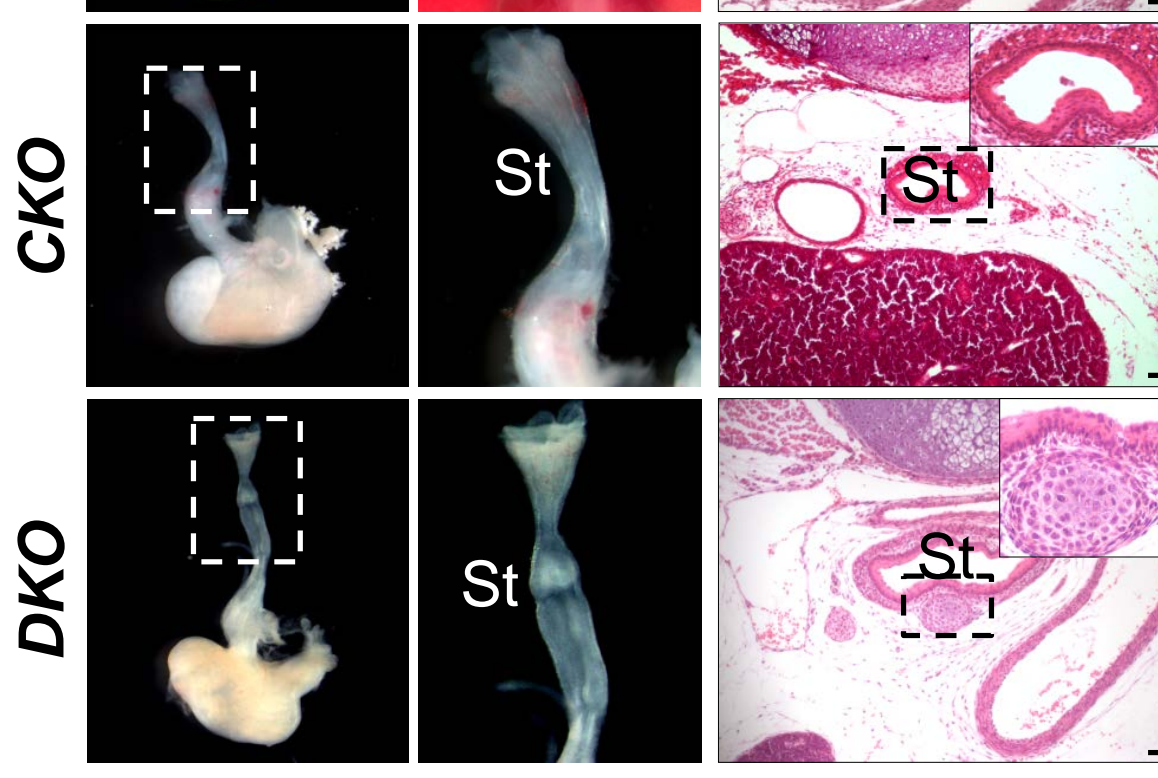

$i^{2}$,

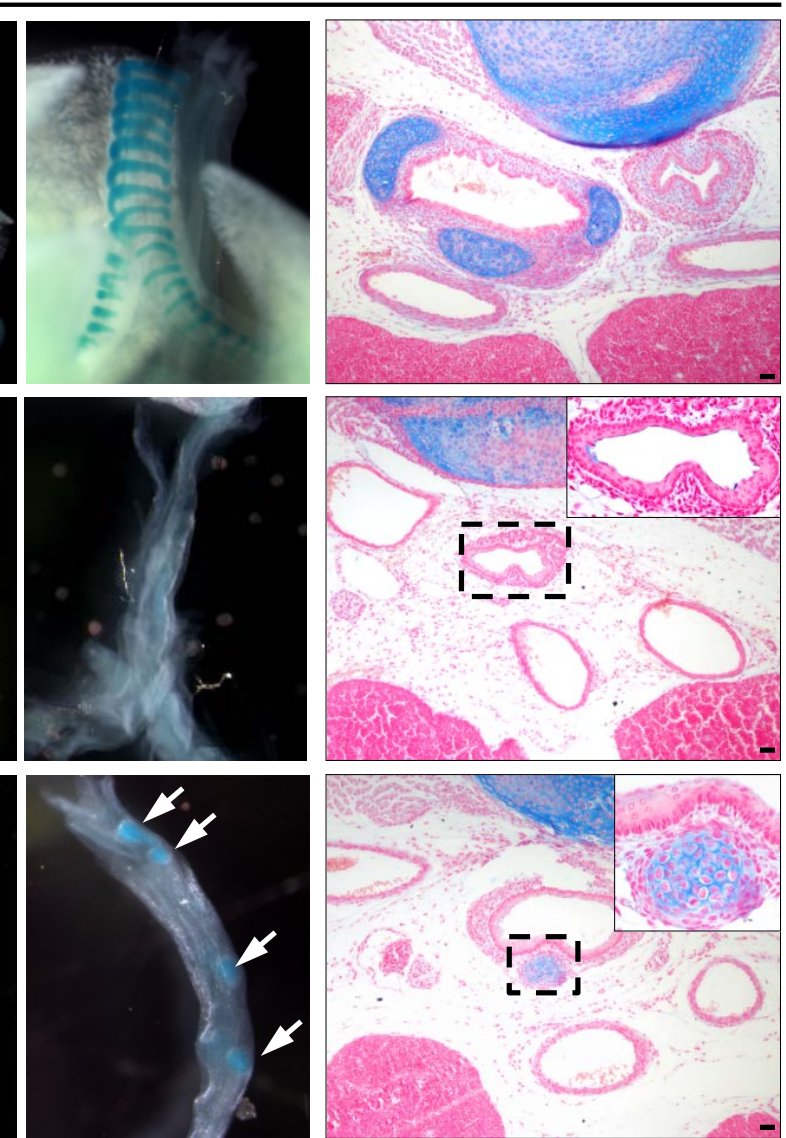

B

p63 Nkx2.1

C Sox9 Nkx2.1
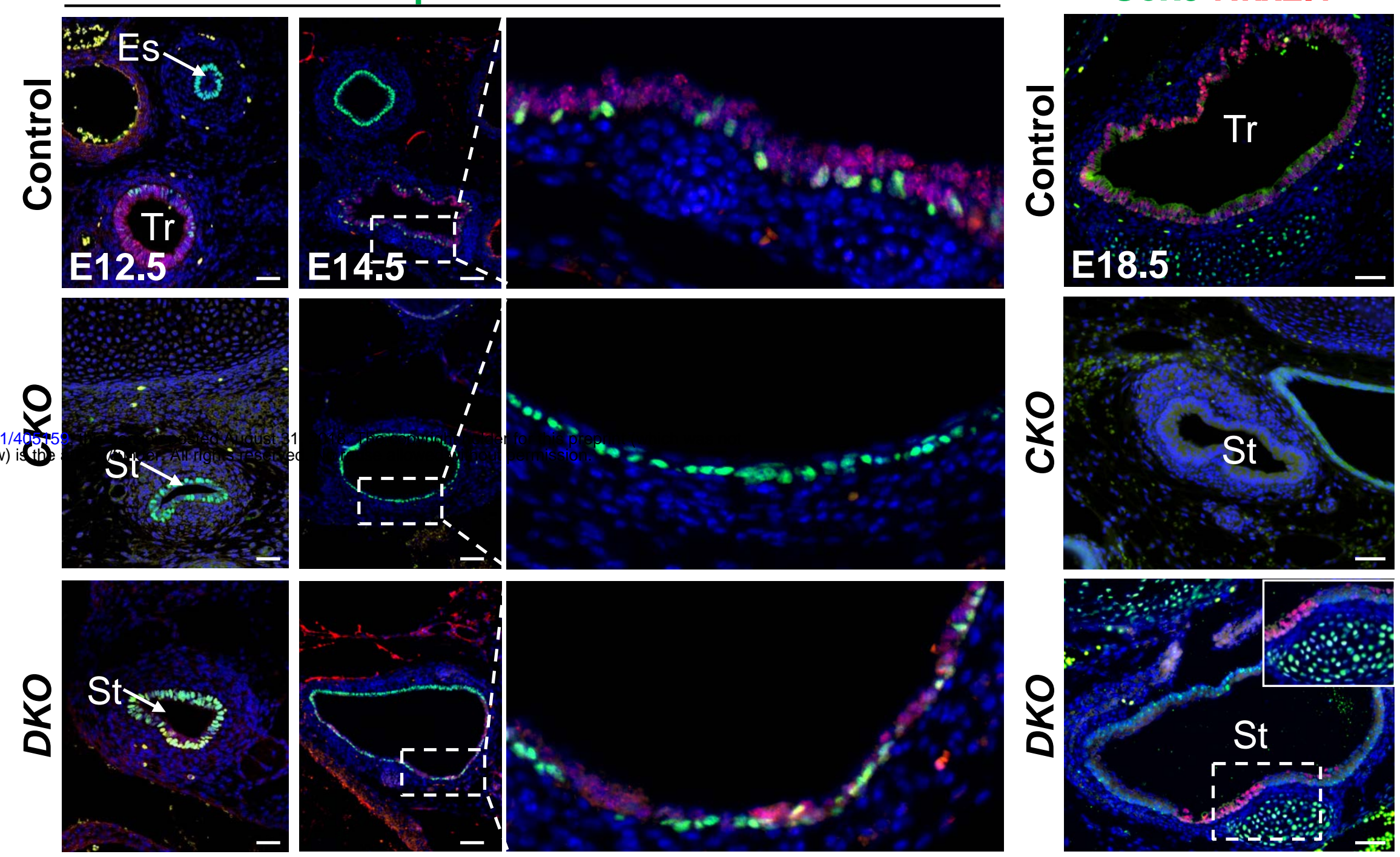
Fig. 3

\section{A}

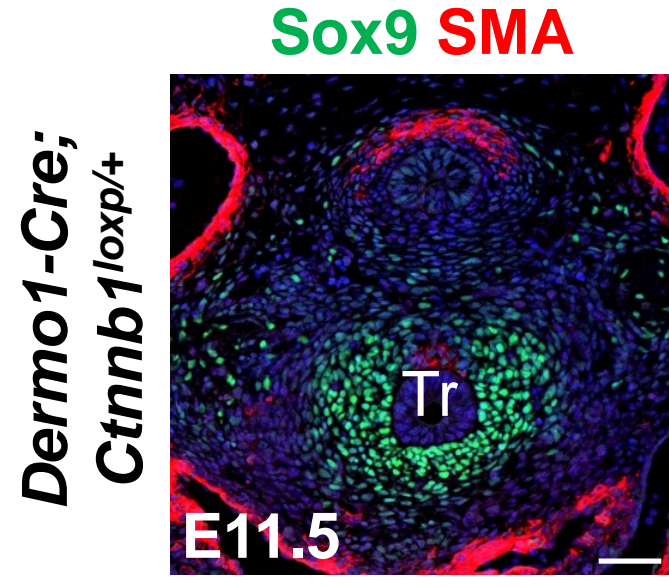

H\&E

Sox9 SMA
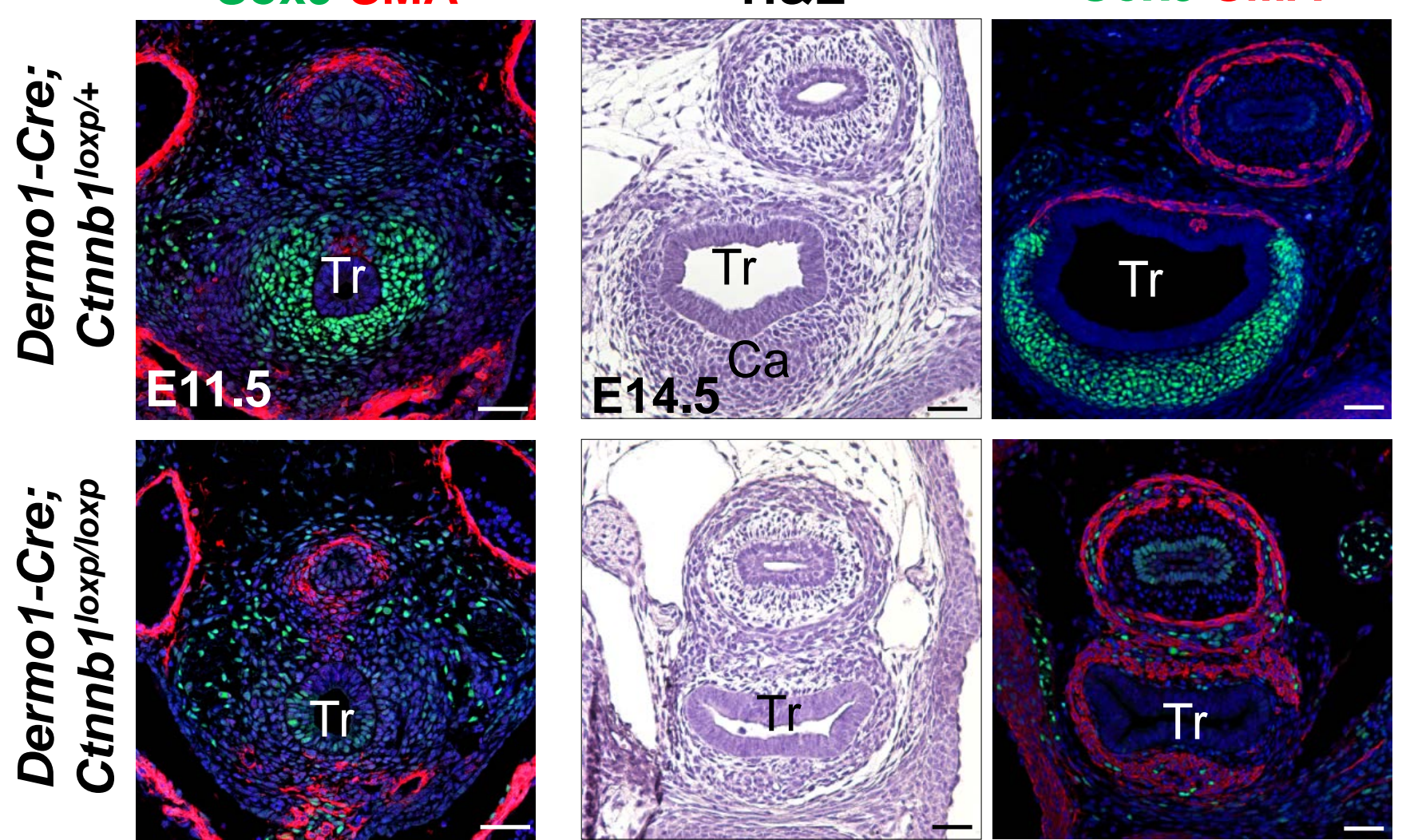

B

Nkx2.1 p63
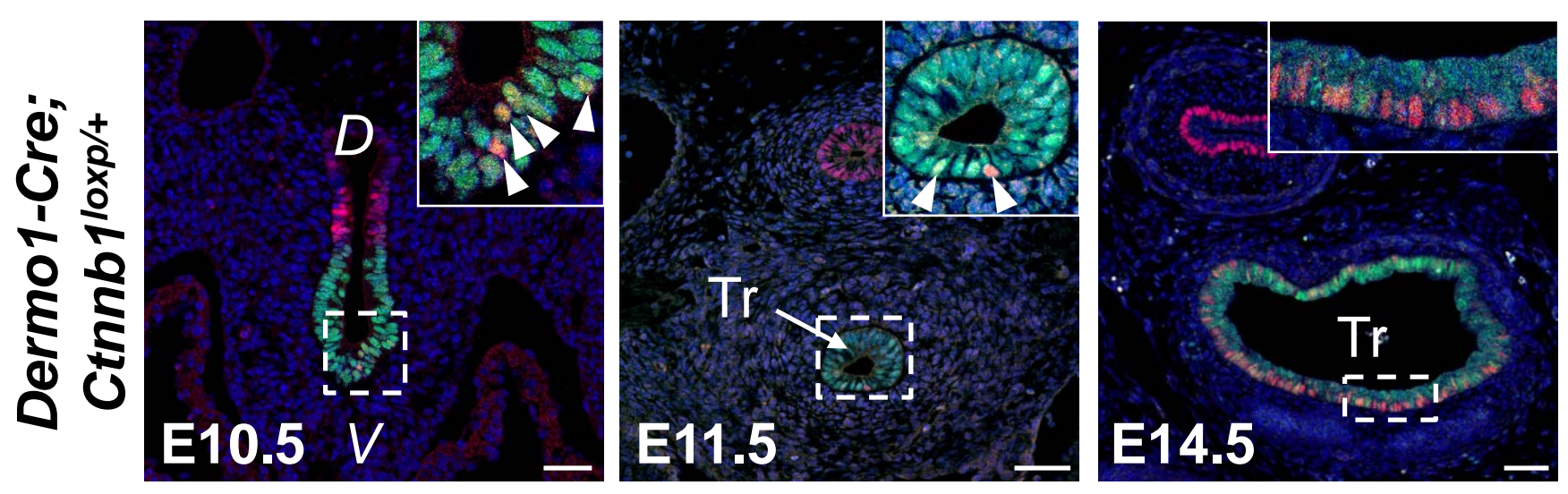

bioRxiv preprint doi: https://doi.org/10.1101/405159; this version poste
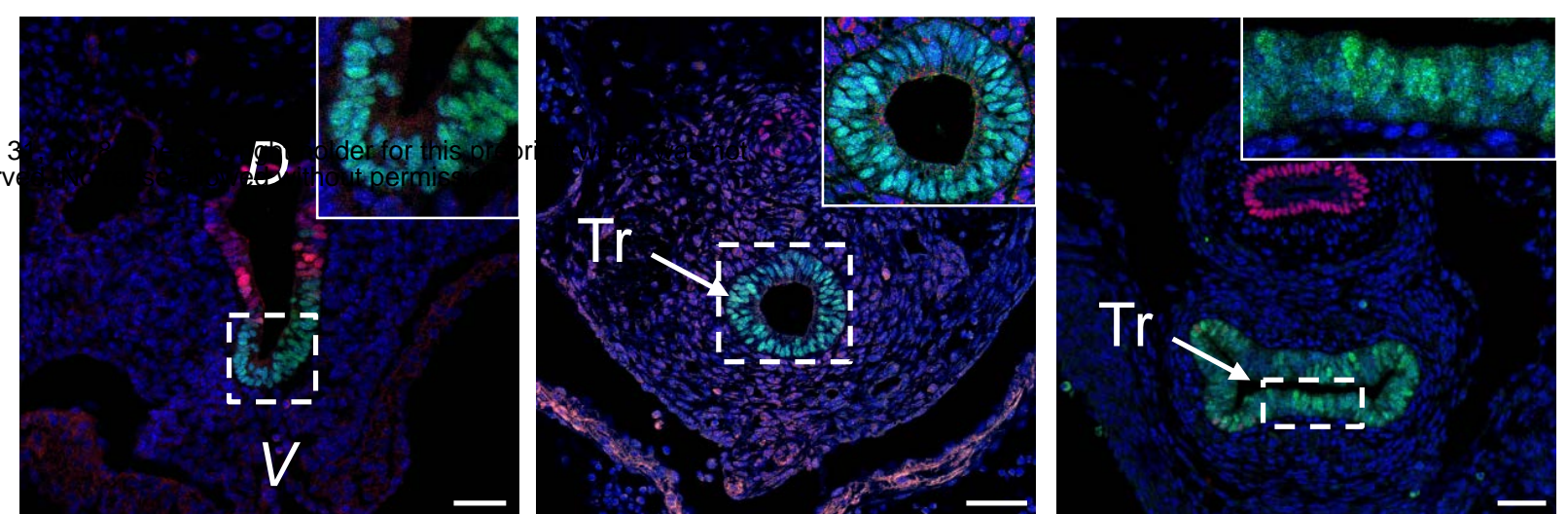
Fig. 4

A

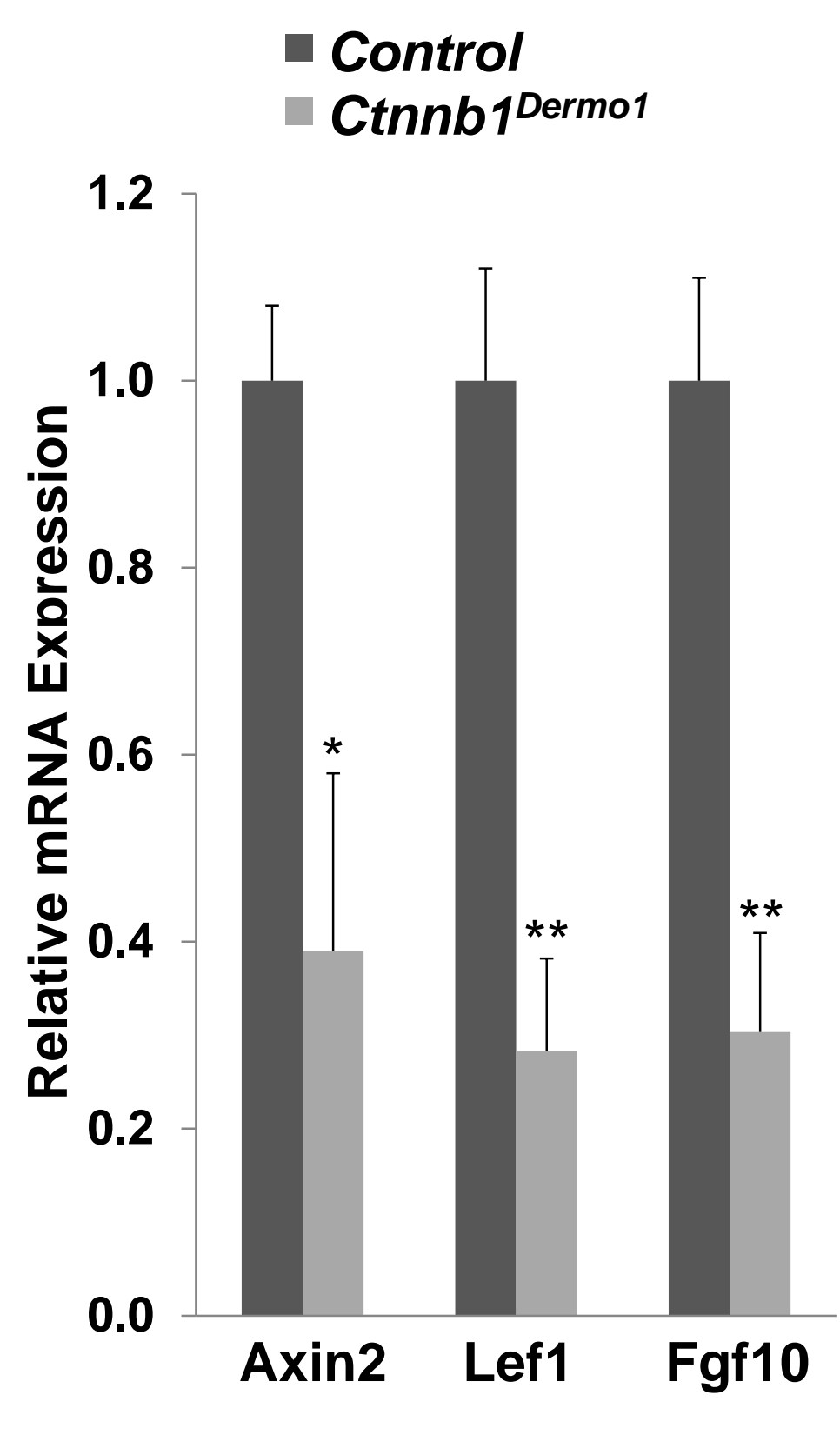

B

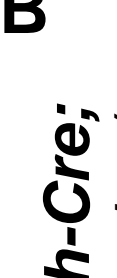

它走

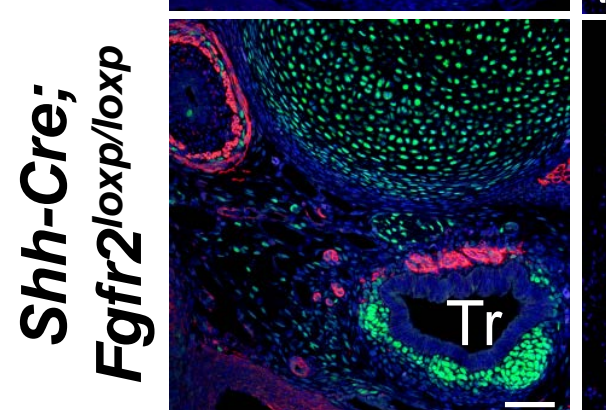

C

C $\quad N k x 2.1 \mathrm{p} 63$

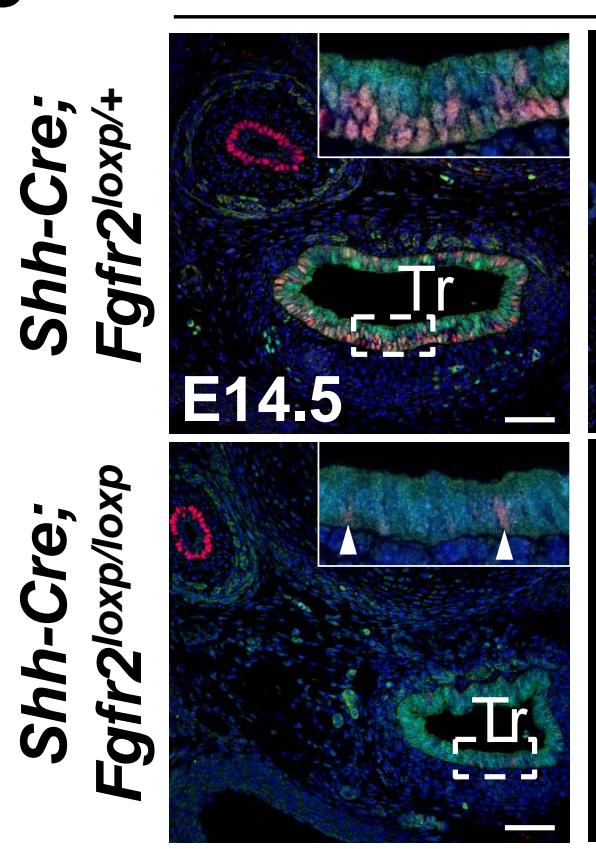

Sox9 SMA
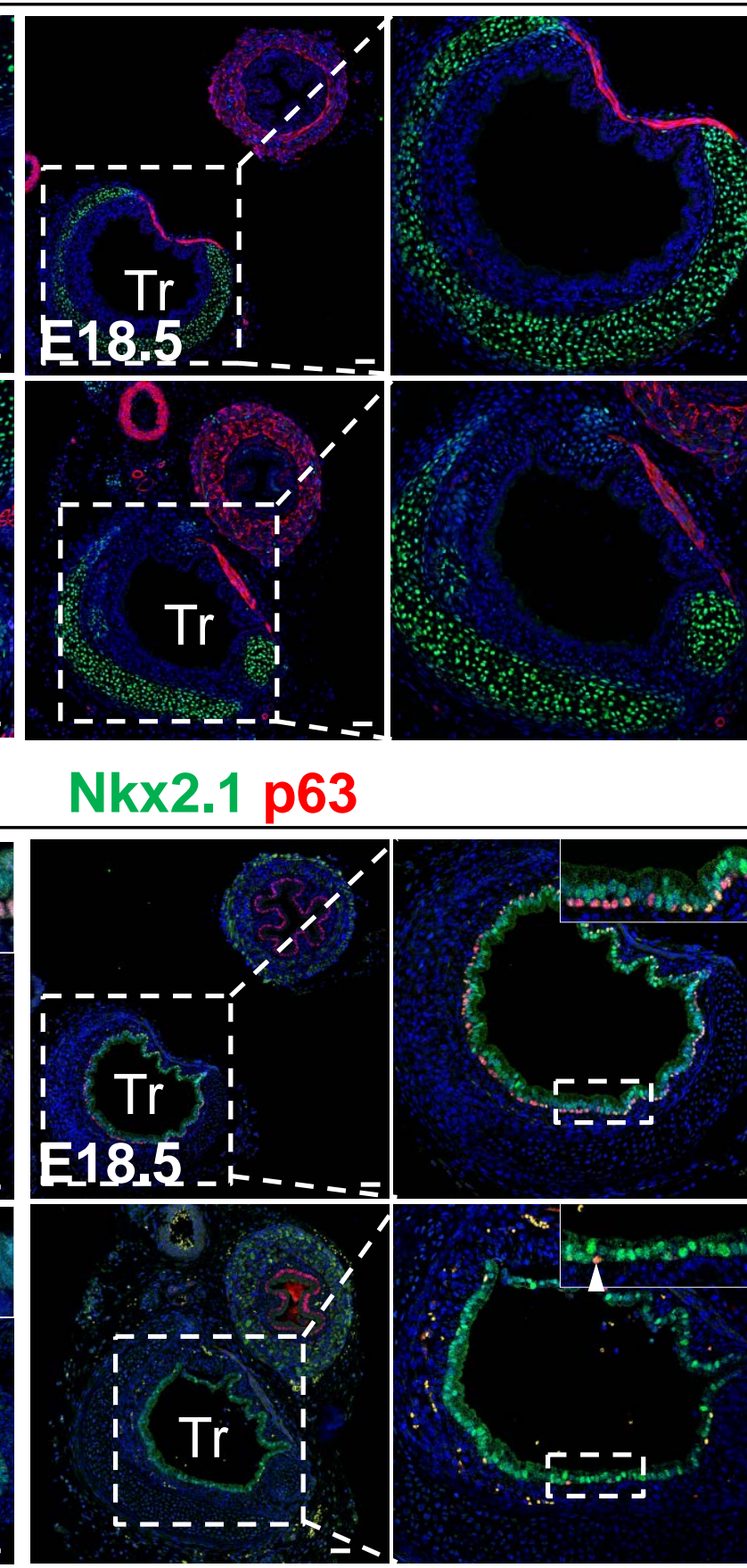

D Trachea
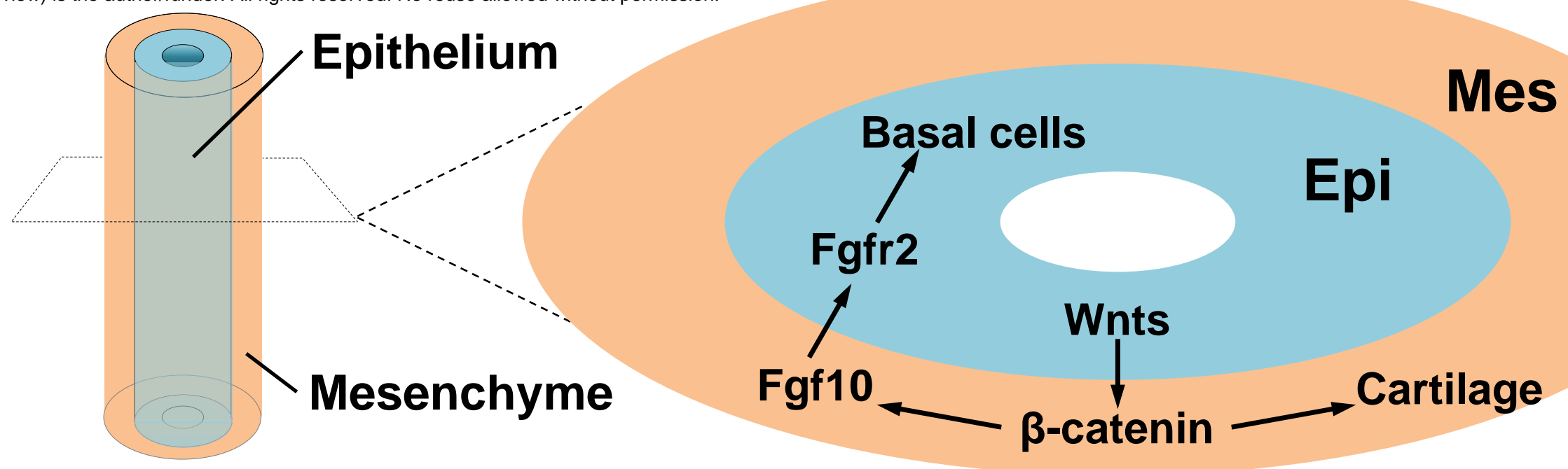
Fig. S1
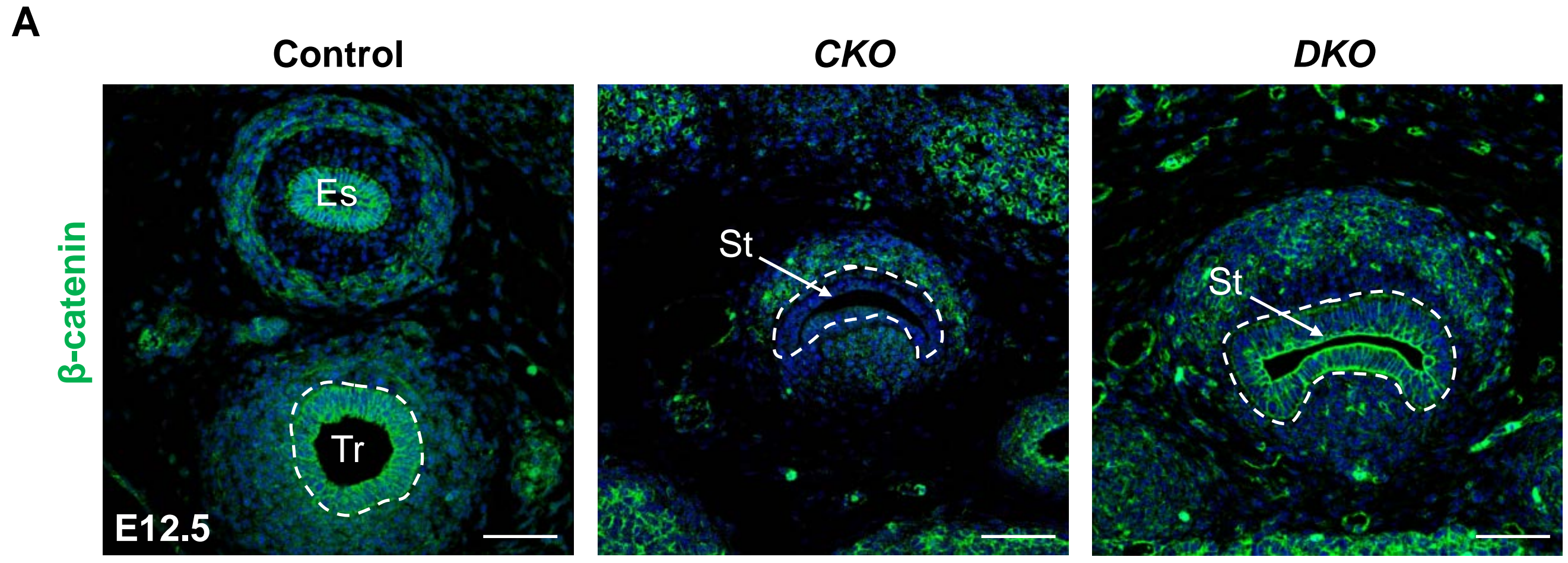
Fig. S2

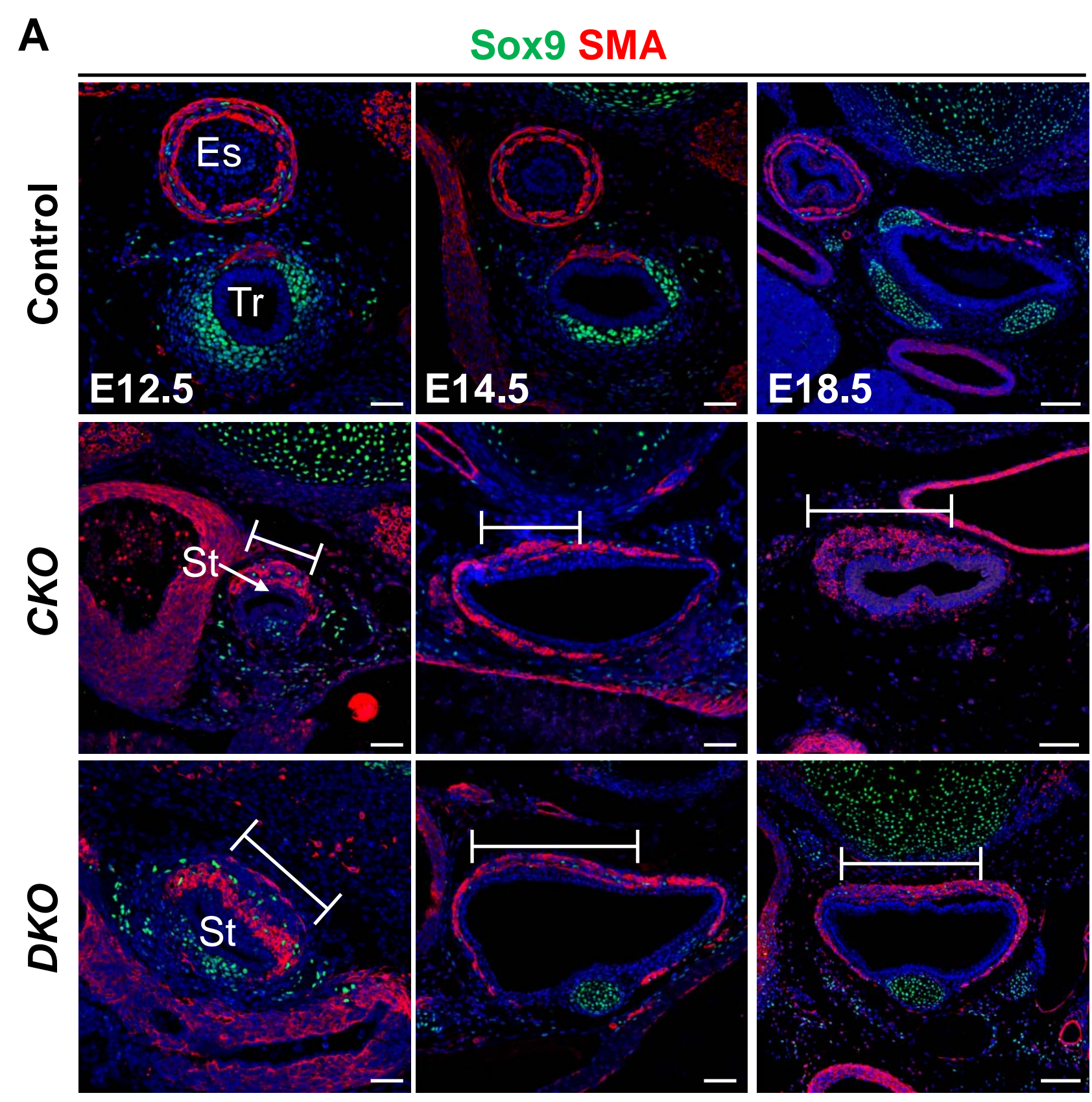

B

Krt8

Krt13
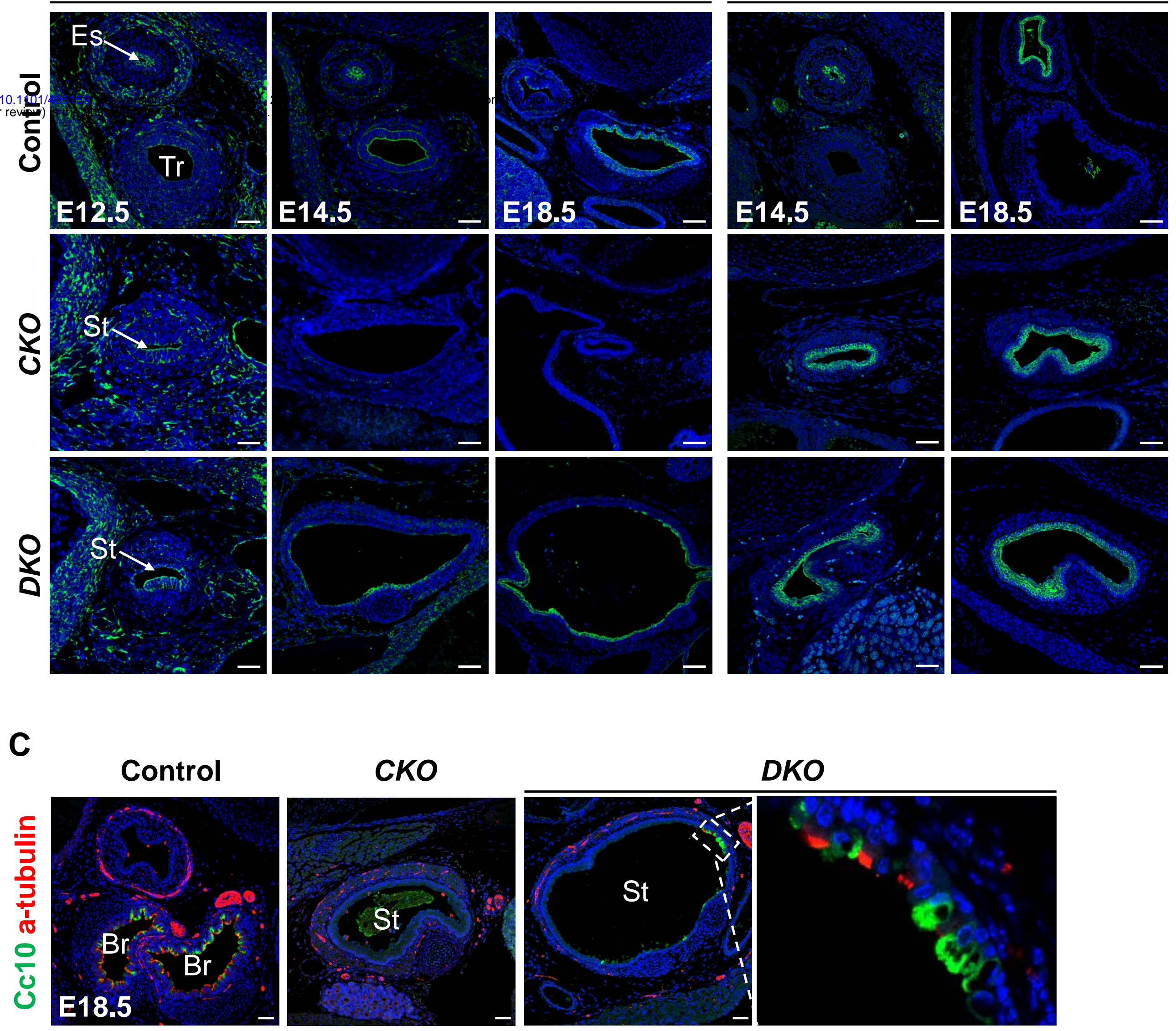